\title{
Socioeconomic variations in hysterectomy: evidence from a linkage study of the Finnish hospital discharge register and population
} census

\author{
Riita Luoto, Ilmo Keskimäki, Antti Reunanen
}

National Public Health Institute, Department of Epidemiology and Health Promotion, Mannerheimintie 166, FIN-00300 Helsinki, Finland.

R Luoto

National Research and Development Centre for Welfare and Health, Health Services Research Unit, Helsinki, Finland.

I Keskimäki

National Public Health Institute, Department of Health and Disability, Helsinki, Finland

A Reunanen

Correspondence to: Dr R Luoto.

Accepted for publication June 1996

\begin{abstract}
Study objective - To explore variations in rates for hysterectomy in relation to social class, education, and family income.

Design - Retrospective analysis of the 1988 Finnish hospital discharge register linked individually to the 1987 population census. Setting - Finland.

Participants - All women living in Finland aged 35 and over were the denominator population. The numerators were the 8663 women who underwent hysterectomy in 1988.

Main results - The overall rate for hysterectomy was $63.5 / 10000$ women aged 35 and over. There was a marked positive correlation between disposable family income and hysterectomy rates even after age, hospital catchment area, education, and occupational status were adjusted for. However, no linear trend for overall hysterectomy rates was observed in relation to social class or education. Procedures due to myomas, accounting for $\mathbf{4 8 \%}$ of all hysterectomies, were more frequent among women of high socioeconomic status according to all socioeconomic indicators. Larger proportions of hysterectomies for myoma were also performed in patients in private hospitals and in pay beds in public hospitals than in women in worse off groups.

Conclusions - Unlike the findings in earlier studies from other countries, there was a positive correlation between income and hysterectomy rates as a result of the high numbers of hysterectomies performed to treat myoma in the well off women. The findings are discussed in terms of socioeconomic differences in the use of private gynaecological services, and factors, such as parity and use of hormonal replacement therapy, that affect the growth of myomas.
\end{abstract}

(f Epidemiol Community Health 1997;51:67-73)

Hysterectomy, removal of the uterus, is one of the most common operations performed in women. In Finland, as well as in Great Britain, every fifth woman aged 45 to 64 years has undergone hysterectomy. ${ }^{123}$ However, clinical criteria for hysterectomy are still under discussion. Several studies have shown wide regional variations in the rates of hysterectomy both internationally and nationally. ${ }^{45} \mathrm{~A}$ recent study $^{6}$ on surgery rates in Denmark, Finland, Norway, and Sweden showed a greater than twofold variation in hysterectomy rates between these, in many respects similar, countries. In this study, the highest national hysterectomy rate was in Finland. ${ }^{6}$ At the same time, the variation within the countries themselves was from 2.6 fold in Denmark to over 10 fold in Norway.

In addition to regional variations, there are sociodemographic differences in the occurrence of hysterectomy (table 1). In previous studies, ${ }^{7-11} 13-16$ education has most often been considered as an indicator of social status. The main trend in those studies has been the higher prevalence of hysterectomy in lower educational and income groups. The same was also true in the single earlier study concerning Finland, in which the proportion of women in the highest education group who had undergone hysterectomy was $13 \%$ and that in the lowest educated group was $22 \% .^{2}$ In this study, ${ }^{2}$ women in the lower white collar group had a higher proportion of hysterectomy than those in the upper white collar group, but the difference was not statistically significant. However, in previous studies there may have been methodological oversights, as the results were mostly based on past data for hysterectomies or information on socioeconomic status was based on geographical proxies, not on individual data.

We aimed to evaluate socioeconomic patterns in clinical practices concerning hysterectomy and to assess differences in access to this operation. In this study we explore socioeconomic variations in rates for hysterectomy in Finland in relation to the indications, surgical approach, occupational status, education, and family income. By using an administrative hospital database individually linked to population census files we have tried to avoid the methodological problems of earlier studies.

\section{Methods}

This study was based on all 8663 hysterectomies performed in 1988 in Finnish hospitals in women aged 35 or more. The data on hysterectomies were obtained from the Finnish hospital discharge register, which contains sum- 
Table 1 Socioeconomic variation in hysterectomy - findings from previous studies

\begin{tabular}{|c|c|c|c|c|c|}
\hline Reference $(y)$ & $\begin{array}{l}\text { Sample } \\
\text { size }\end{array}$ & Origin of sample & $\begin{array}{l}\text { Indicator of } \\
\text { socioeconomic status }\end{array}$ & Adjusting variables & Finding \\
\hline Bunker $^{7}$ (1974) & 7400 & $\begin{array}{l}\text { Selected professionals, } \\
\text { California }\end{array}$ & $\begin{array}{l}\text { Groups of selected } \\
\text { professionals and their } \\
\text { spouses }\end{array}$ & - & $\begin{array}{l}\text { Spouses of male physicians before } \\
\text { hysterectomy } 22.6(1.3) \% \text {, spouses of } \\
\text { professionals } 17.3(1.4) \% \text {, p<0.01 }\end{array}$ \\
\hline Koepsell $^{8}(1980)$ & 1087 & $\begin{array}{l}\text { Random, two Washington } \\
\text { counties }\end{array}$ & $\begin{array}{l}\text { Education } \\
\text { Income on census } \\
\text { tract level }\end{array}$ & $\begin{array}{l}\text { Age, sociodemographic and } \\
\text { reproductive factors, health } \\
\text { conditions, health practices }\end{array}$ & $\begin{array}{l}\text { Highest income quartile } 28 \% \text { before } \\
\text { hysterectomy, lowest } 49 \%, p<0.001\end{array}$ \\
\hline Coulter' (1985) & 4120 & Random, Oxford & $\begin{array}{l}\text { Occupation } \\
\text { Education }\end{array}$ & Age, parity & $\begin{array}{l}\text { No social class difference, if private } \\
\text { surgery included } \\
\text { Age at completion of education }<16 \text { y } \\
\text { before hysterectomy } 19 \%,>19 \text { y } 14 \%\end{array}$ \\
\hline Meilahn $^{10}(1989)$ & 2137 & $\begin{array}{l}\text { Random, driver's license } \\
\text { lists, Pittsburgh }\end{array}$ & Education & $\begin{array}{l}\text { Age at birth of first child, } \\
\text { age at menarche, education }\end{array}$ & $\begin{array}{l}\text { Highest educated odds of prior } \\
\text { hysterectomy } 0.69 \text { ( } 95 \% \text { CI } 0.56 \text {, } \\
0.86) v \text { lowest educated (ref) }\end{array}$ \\
\hline Schofield ${ }^{11}$ (1991) & 8896 & $\begin{array}{l}\text { Random, North South } \\
\text { Wales, Australia }\end{array}$ & $\begin{array}{l}\text { Education } \\
\text { Husband's } \\
\text { occupational status }\end{array}$ & - & $\begin{array}{l}83 \% \text { of those who had hysterectomy } \\
\text { were not educated beyond middle } \\
\text { high school. Husbands of } 63 \% \text { of } \\
\text { women in the lower occupational } \\
\text { status, } 18 \% \text { in the higher levels }\end{array}$ \\
\hline Gittelsohn $^{12}(1991)$ & 28891 & $\begin{array}{l}\text { Hospital discharge data on } \\
\text { Maryland, income data } \\
\text { from census }\end{array}$ & Income & Age, area & $\begin{array}{l}\text { Lowest income group odds of } \\
\text { hysterectomy } 1.2 v \text { highest income } \\
\text { group }\end{array}$ \\
\hline Luoto $^{2}(1992)$ & 1713 & Random, Finland & $\begin{array}{l}\text { Occupation } \\
\text { Education }\end{array}$ & Age & $\begin{array}{l}\text { Highest educated before hysterectomy } \\
13 \% \text {, lowest educated } 22 \%, \mathrm{p}<0.001 \text {. }\end{array}$ \\
\hline Vessey $^{13}(1992)$ & 17032 & $\begin{array}{l}\text { Selected, British married } \\
\text { women using the pill or an } \\
\text { IUD as contraception }\end{array}$ & Husband's social class & $\begin{array}{l}\text { Parity, indication for } \\
\text { hysterectomy }\end{array}$ & $\begin{array}{l}\text { Significant trend towards higher rates } \\
\text { for hysterectomies for menstrual } \\
\text { problems and non-significant trend } \\
\text { towards lower rates for fibroids and } \\
\text { endometriosis in lower social classes }\end{array}$ \\
\hline Santow $^{14}(1992)$ & 2547 & Random, Australia & Education & $\begin{array}{l}\text { Age, parity, reproductive } \\
\text { factors, education, area }\end{array}$ & $\begin{array}{l}\text { University educated odds of prior } \\
\text { hysterectomy } 0.58 v \text { lower educated } \\
\text { (ref) }\end{array}$ \\
\hline Kjerulff $^{15}$ (1993) & 12465 & Random, 15 states in USA & $\begin{array}{l}\text { Education } \\
\text { Income }\end{array}$ & Age & $\begin{array}{l}\text { Lowest income quartile odds of prior } \\
\text { hysterectomy } 1.6(95 \% \text { CI } 1.2,2.0) v \\
\text { highest (ref). Lowest educated odds of } \\
\text { prior hysterectomy } 2.1 \text { ( } 95 \% \text { CI } 1.7 \text {, } \\
2.7) v \text { highest (ref) }\end{array}$ \\
\hline $\mathrm{Kuh}^{16}(1995)$ & 1628 & Random, Britain & $\begin{array}{l}\text { Education } \\
\text { Own and husband's } \\
\text { social class }\end{array}$ & Age, parity & $\begin{array}{l}\text { Highest educated women had lowest } \\
\text { risk for hysterectomy }\end{array}$ \\
\hline
\end{tabular}

mary information on each inpatient episode from all public and private hospitals since 1969. ${ }^{17}$ Diagnoses and dates of hospital admission and discharge have been included in the register since its inception, but recording of surgical procedures started in 1986. The register also contains data on patients treated as private (pay bed) patients in public hospitals.

The reliability of the Finnish hospital discharge register has been considered to be good. It has been estimated that the register covers $90-95 \%$ of all surgical procedures, and principal diagnoses are identical with the diagnosis in the medical records in $95 \%$ of discharges. ${ }^{518}$

The discharge register data on hysterectomies were linked by the patients' personal identification numbers with the 1987 population census in order to obtain data on the patients' occupation, education, family structure, and income. The census was also used to derive data on populations at risk. In order to obtain the data on occupational status for retired women, the 1987 census files were supplemented with the data on occupation before retirement in the $1970,1975,1980$, and 1985 censuses. Women were classified according to their own occupation or, if they were not employed, their husband's occupation.

Social class was defined according to occupational group ${ }^{19}$ as follows:

1. Upper white collar employees: upper level administrative, managerial or professional employees,

2. Lower white collar employees: lower level administrative or clerical employees,

3. Blue collar workers: skilled or unskilled manual workers,
4. Farmers: farmer employers or farmers on own account,

5. Others: employers or self employed workers, students, and those with unknown occupation.

Education was divided into three categories: high, medium, and low. People with a university degree or a qualification requiring 13 years or more of education were included in high education group. Medium education was defined as secondary school and vocational training, or high school matriculation requiring 10-12 years of education. Low education corresponds to a basic education of fewer than 10 years.

The data on disposable family income were based on the registries of taxation and welfare benefits. Income was adjusted for family size using the OECD equivalence scale, where the first adult of a family is weighed as 1.0 , other adults 0.7 , and children less than 18 years old $0.5 .^{20}$

Since 1986, surgical procedures in the Finnish hospital discharge register have been coded according to the classification of procedures by the Finnish Hospital League. ${ }^{21}$ In the classification, hysterectomies were classified in relation to the surgical approach as follows:

1. Subtotal hysterectomy,

2. Hysterectomy without oophorectomy, hysterectomy with unilateral oophorectomy,

3. Hysterectomy with bilateral oophorectomy, or

4. Vaginal hysterectomy.

The combination of subtotal hysterectomy and bilateral oophorectomy is extremely rare, and therefore all subtotal hysterectomies are summed together. 


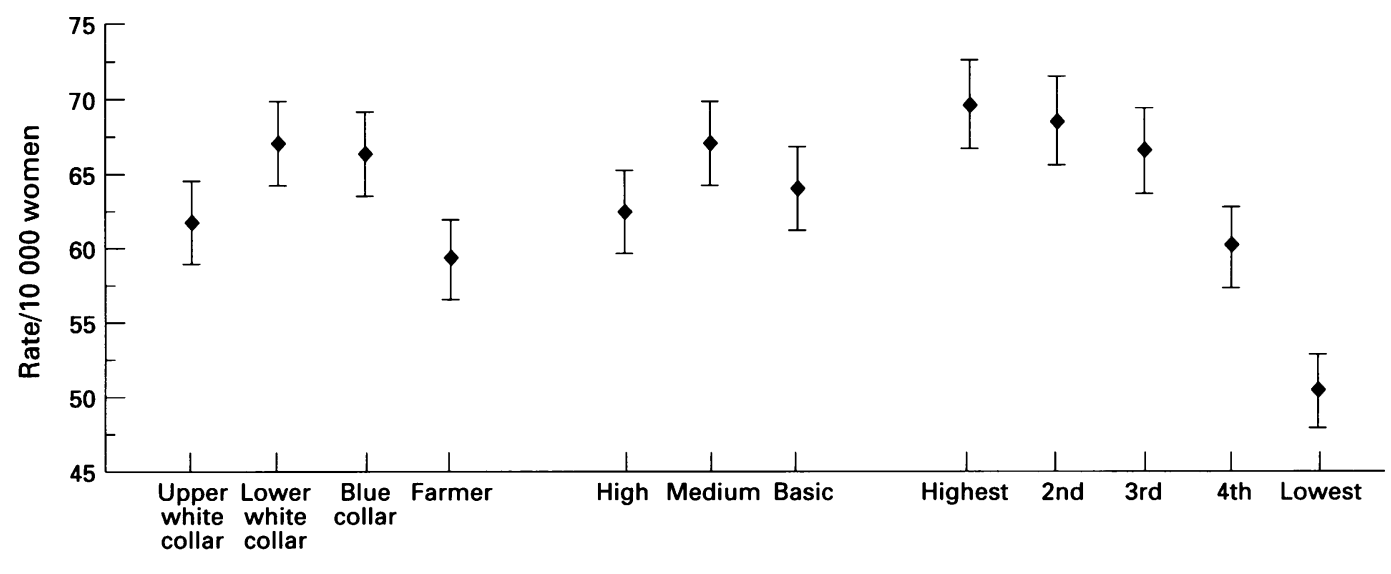

Social class

Education

Disposable income

Figure 1 Age adjusted rates for hysterectomy in relation to social class, education, and disposable income.

Table 2 Hysterectomy rates per 10000 women aged 35 or more adjusted for age in relation to socioeconomic status and indication for surgery, Finland 1988

\begin{tabular}{|c|c|c|c|c|c|c|c|}
\hline \multirow{3}{*}{ Socioeconomic status } & \multicolumn{7}{|c|}{ Indications for hysterectomy } \\
\hline & Myoma & Endometriosis & Prolapse & $\begin{array}{l}\text { Disorders of } \\
\text { menstruation }\end{array}$ & $\begin{array}{l}\text { Other benign } \\
\text { indications }\end{array}$ & $\begin{array}{l}\text { Malign } \\
\text { indications }\end{array}$ & Total \\
\hline & Rate (\%) & Rate (\%) & Rate (\%) & Rate (\%) & Rate (\%) & Rate (\%) & Rate \\
\hline $\begin{array}{l}\text { Social class: } \\
\text { Upper white collar } \\
\text { Lower white collar } \\
\text { Blue collar } \\
\text { Farmers }\end{array}$ & $\begin{array}{l}33.6(54) \\
33.6(50) \\
28.9(44) \\
25.0(42)\end{array}$ & $\begin{array}{l}5.5(9) \\
7.5(11) \\
6.8(10) \\
4.6(8)\end{array}$ & $\begin{array}{l}5.7(9) \\
5.0(7) \\
5.7(9) \\
7.6(13)\end{array}$ & $\begin{array}{l}3.4(5) \\
4.5(7) \\
6.6(10) \\
6.3(11)\end{array}$ & $\begin{array}{l}10.1(16) \\
11.7(17) \\
14.2(21) \\
12.2(20)\end{array}$ & $\begin{array}{l}3.6(6) \\
4.7(7) \\
4.1(6) \\
3.8(6)\end{array}$ & $\begin{array}{l}61.9 \\
67.0 \\
66.3 \\
59.4\end{array}$ \\
\hline $\begin{array}{l}\text { Education: } \\
\text { High } \\
\text { Medium } \\
\text { Basic }\end{array}$ & $\begin{array}{l}33.6(54) \\
21.4(47) \\
29.7(46)\end{array}$ & $\begin{array}{l}5.6(9) \\
6.9(10) \\
7.1(11)\end{array}$ & $\begin{array}{l}5.1(8) \\
6.9(10) \\
5.3(8)\end{array}$ & $\begin{array}{l}2.9(5) \\
5.0(8) \\
5.2(8)\end{array}$ & $\begin{array}{l}11.0(18) \\
12.3(18) \\
12.7(20)\end{array}$ & $\begin{array}{l}4.2(7) \\
4.6(7) \\
3.9(6)\end{array}$ & $\begin{array}{l}62.5 \\
67.0 \\
64.0\end{array}$ \\
\hline $\begin{array}{l}\text { Disposable income: } \\
\text { Highest } \\
\text { 2nd } \\
\text { 3rd } \\
\text { 4th } \\
\text { Lowest }\end{array}$ & $\begin{array}{l}37.6(54) \\
32.8(48) \\
28.9(43) \\
25.9(43) \\
19.4(38)\end{array}$ & $\begin{array}{l}7.0(10) \\
7.4(11) \\
6.8(10) \\
6.1(10) \\
5.5(11)\end{array}$ & $\begin{array}{l}5.3(8) \\
6.2(9) \\
6.2(9) \\
6.2(10) \\
5.5(11)\end{array}$ & $\begin{array}{l}3.6(5) \\
5.2(8) \\
6.1(9) \\
5.8(10) \\
4.4(9)\end{array}$ & $\begin{array}{l}11.7(17) \\
12.3(18) \\
14.1(21) \\
12.1(20) \\
11.3(22)\end{array}$ & $\begin{array}{l}4.4(6) \\
4.5(7) \\
4.3(7) \\
4.0(7) \\
4.1(8)\end{array}$ & $\begin{array}{l}69.5 \\
68.4 \\
66.4 \\
60.1 \\
50.4\end{array}$ \\
\hline Total & $30.2(48)$ & $6.7(11)$ & $5.5(9)$ & $4.9(8)$ & $11.9(19)$ & $4.2(7)$ & 63.5 \\
\hline
\end{tabular}

In 1988, diagnoses in the register were coded by the International Classification of Diseases, 9 th revision (ICD-9). The categories of indications associated with hysterectomy in the study were benign neoplasms, especially myomas (ICD-9: 218), other fibroids (ICD-9: 219-221), other disorders of the female genital tract including endometriosis (ICD-9: 617), genital prolapse (ICD-9: 618), disorders of menstruation (ICD-9: 626), genital infections (ICD-9: 614-616), and malign neoplasms (ICD-9: 179-183).

The statistical analysis was based on multidimensional tabulations of the data on hysterectomies and the population at risk in relation to age, socioeconomic indicators, and hospital catchment areas. The methods for defining hospital catchment areas are described in detail by Keskimäki et al. ${ }^{5}$ Rates of hysterectomy and $95 \%$ confidence intervals $(95 \%$ CI) were related to the size of the population in each age group. Direct age adjustment was performed by using all Finnish women as the standard population. Differences in the incidence of hysterectomy in relation to socioeconomic position were estimated through Poisson regression models using the GLIM program package. ${ }^{22}$ Results were adjusted for age and hospital catchment area because of the over threefold regional differences in hysterectomy rates in Finland.

\section{Results}

The total 1988 rate for hysterectomy in Finland was 63.5 per 10000 women. The rate was highest for women with the highest family income. Relative socioeconomic differences were also largest across income groups. According to social class and education, hysterectomy rates were highest among lower white collar women, blue collar women, or those who had received a medium education (figure 1 ).

The most frequent indication for hysterectomy was myoma, which accounted for nearly half of all the operations (table 2). The rates for myomas were higher among women with high socioeconomic status according to all three socioeconomic indicators - the difference was even twofold across income groups. Hysterectomies due to disorders of menstruation tended to be more common in lower socioeconomic groups. Prolapse was more prevalent and endometriosis less prevalent among farmers compared with other groups. For malign 
Table 3 Hysterectomy rates per 10000 women aged 35 or more for hysterectomy due to benign indications adjusted for age in relation to socioeconomic status and surgical approach, Finland 1988

\begin{tabular}{|c|c|c|c|c|c|c|}
\hline \multirow[b]{2}{*}{ Socioeconomic status } & \multicolumn{6}{|c|}{ Surgical approaches } \\
\hline & $\begin{array}{l}\text { Hysterectomy } \\
\text { and unilateral } \\
\text { oophorectomy } \\
\text { Rate (\%) }\end{array}$ & $\begin{array}{l}\text { Subtotal } \\
\text { hysterectomy } \\
\text { Rate (\%) }\end{array}$ & $\begin{array}{l}\text { Hysterectomy } \\
\text { and bilateral } \\
\text { oophorectomy } \\
\text { Rate (\%) }\end{array}$ & $\begin{array}{l}\text { Vaginal } \\
\text { hysterectomy } \\
\text { Rate (\%) }\end{array}$ & $\begin{array}{l}\text { Other } \\
\text { approaches } \\
\text { Rate (\%) }\end{array}$ & $\begin{array}{l}\text { Total } \\
\text { Rate }\end{array}$ \\
\hline \multicolumn{7}{|l|}{ Social class: } \\
\hline Upper white collar & $27.9(48)$ & $11.3(19)$ & $12.9(22)$ & $5.6(10)$ & $0.5(1)$ & 58.2 \\
\hline Lower white collar & $30.8(49)$ & $12.7(20)$ & $13.5(22)$ & $5.0(8)$ & $0.3(1)$ & 62.3 \\
\hline Blue collar & $27.7(45)$ & $15.2(24)$ & $13.3(21)$ & $5.7(9)$ & $0.3(1)$ & 62.2 \\
\hline Farmer & $19.1(34)$ & $15.5(28)$ & $14.0(25)$ & $6.7(12)$ & $0.3(1)$ & 55.6 \\
\hline \multicolumn{7}{|l|}{ Education: } \\
\hline High & $28.9(50)$ & $10.1(17)$ & $13.8(24)$ & $4.8(8)$ & $0.6(1)$ & 58.2 \\
\hline Medium & $28.9(46)$ & $13.0(21)$ & $13.2(21)$ & $7.0(11)$ & $0.3(1)$ & 62.5 \\
\hline Basic & $27.7(46)$ & $14.1(23)$ & $12.9(21)$ & $5.1(9)$ & $0.3(1)$ & 60.1 \\
\hline \multicolumn{7}{|l|}{ Disposable income: } \\
\hline Highest & $31.7(49)$ & $13.6(21)$ & $14.3(22)$ & $5.2(8)$ & $0.3(-)$ & 65.1 \\
\hline 2nd & $29.2(46)$ & $13.5(21)$ & $14.8(23)$ & $6.0(9)$ & $0.3(1)$ & 63.9 \\
\hline 3 rd & $29.0(47)$ & $14.0(23)$ & $12.6(20)$ & $6.1(10)$ & $0.4(1)$ & 62.0 \\
\hline 4th & $25.2(45)$ & $12.7(23)$ & $11.7(21)$ & $6.1(11)$ & $0.3(1)$ & 56.2 \\
\hline Lowest & $18.8(41)$ & $10.7(23)$ & $10.9(23)$ & $5.4(12)$ & $0.6(1)$ & 46.2 \\
\hline Total & $27.6(47)$ & $13.1(22)$ & $12.7(21)$ & $5.5(9)$ & $0.4(1)$ & 59.3 \\
\hline
\end{tabular}

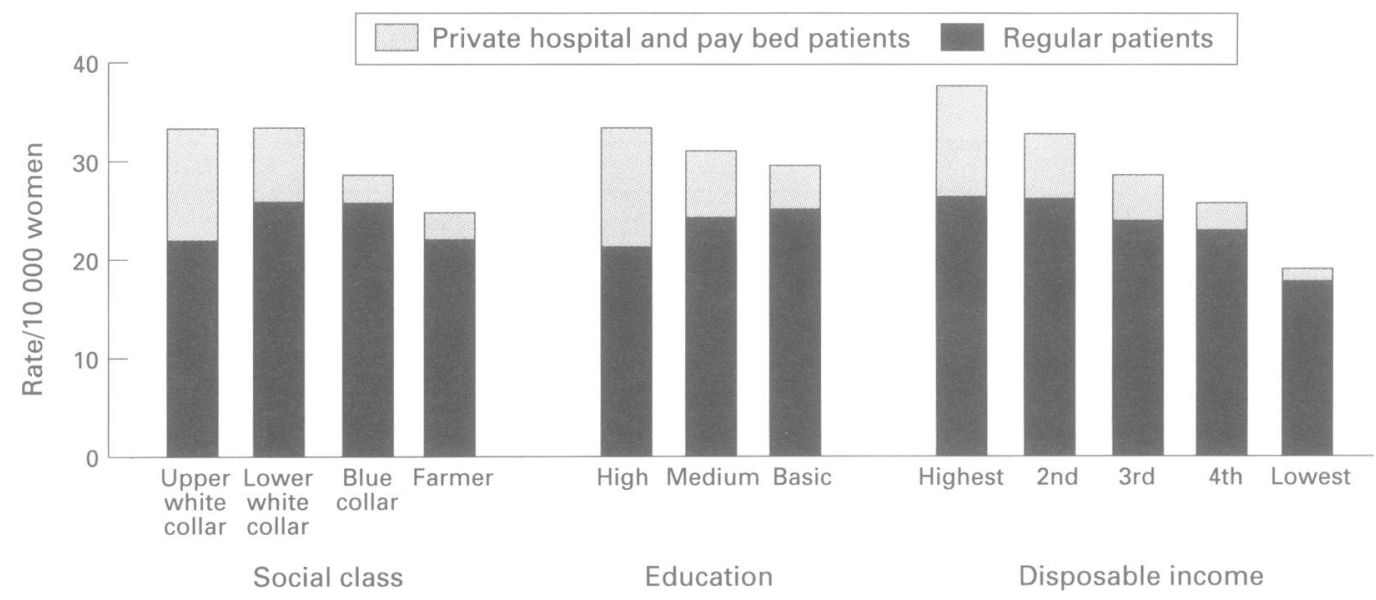

Figure 2 Rates for hysterectomy due to myoma performed in patients in private hospitals and pay beds and patients in public hospitals in relation to social class, education, and disposable income.

indications, there were no systematic rate differences across socioeconomic groups.

The average age at the time of hysterectomy for all operations was $48.3(95 \% \mathrm{CI} 48.1,48.5)$ but it differed between indications and surgical methods. The age at hysterectomy was significantly higher among women who had a hysterectomy due to prolapse compared with those who had a hysterectomy for other indications. Correspondingly, vaginal hysterectomies (mean age $62.0,95 \%$ CI 61.1 , 62.8 ), commonly undertaken for uterine prolapse in Finland, were performed for significantly older women than subtotal hysterectomies (mean age $45.2,95 \%$ CI 44.8 , 45.6) or simple hysterectomies (mean age 43.1, 95\% CI 42.9, 43.2).

Women in the farmer group (mean age 55.3, $95 \%$ CI 54.3, 56.2), with a basic education (mean age $50.7,95 \%$ CI $50.4,51.0$ ) or those among the two lowest income quintiles (mean age $52.9,95 \%$ CI $52.2,53.6$ in the lowest and $51.6,95 \%$ CI $51.0,52.2$ in the 4 th quintile) were significantly older when they underwent hysterectomy than women in the other groups. However, this was mainly due to the age structure of the population at risk in these groups.
There were no significant differences in the mean ages at hysterectomy in indication groups in relation to education or occupation, except for farmers whose age at hysterectomy was higher than in the other groups for all indications. For all indications, women in the highest income category underwent hysterectomy at a younger age than women in the other income categories.

Forty seven per cent of hysterectomies were performed for benign indications with unilateral oophorectomy or no oophorectomy, $21 \%$ were hysterectomies with bilateral oophorectomy, $9 \%$ were vaginal hysterectomies, and $22 \%$ were subtotal hysterectomies (table 3 ). Age adjusted social class differences were largest for hysterectomies with unilateral oophorectomy or no oophorectomy. With regard to income, those in the highest quintile had the highest age adjusted rate for hysterectomy for all surgical approaches except vaginal hysterectomy. Educational differences in respect of surgical approaches were small and contradictory.

The risk for hysterectomy increased linearly in relation to relative income. Adjustment for age and hospital catchment area by Poisson 
regression did not change these relative socioeconomic differences. Nor did the subsequent additions of education and social class to the model modify the income gradient for hysterectomy rates. However, adjustment for income increased the relative rates among women with low education or occupational status.

The proportion of hysterectomies performed in private hospitals was small - less than $1 \%$. On the other hand, $18 \%$ of the hysterectomies were performed in senior physicians' private (pay bed) patients in public hospitals. Figure 2 shows separately the rates for hysterectomies due to myoma performed for regular patients and patients treated in pay beds or in private hospitals. According to all socioeconomic indicators, the higher the socioeconomic status, the larger the proportion of operations performed as private procedures. The findings were similar for other benign indications.

\section{Discussion}

According to our study, Finnish women with a high disposable family income were more likely to undergo hysterectomy than those with a low income, even after age, hospital catchment area, education, and occupational status were adjusted for. However, women with high status according to social class or education had lower hysterectomy rates than lower white collar or blue collar women, and those with medium or basic education.

The positive correlation of operation rates and income was evident regarding procedures due to myomas, which accounted for half of the indications for hysterectomies. Social class and educational gradients in myoma operations also favoured the best off women. For other indications, the differences between socioeconomic groups were less systematic. The rates for procedures undertaken for disorders of menstruation were highest among blue collar women and women with basic education, but with regard to income levels these procedures were most frequent in those with an intermediate income. For malign indications, there were no systematic socioeconomic gradients. With regard to endometriosis, the gradients were more or less opposite for educational and income groups, and for social classes no clear trend existed.

For surgical approaches, our study did not reveal any systematic socioeconomic differences which were unrelated to indications for hysterectomy. For example, women with a farming background had a high rate of vaginal procedures. In Finland this is a common intervention for treating uterine prolapse, a frequent indication among farming women, who tended to be significantly older than women from other socioeconomic groups.

Our findings on trends in hysterectomy rates according to different, highly correlated socioeconomic indicators were partly contradictory. In particular, our findings on the dependency of hysterectomies on family income were opposite to findings from many earlier studies (table 1). In evaluation of these ambiguities several factors should be considered.
The adequacy of socioeconomic indicators in terms of social stratification may be one reason for the contradictory results. The definition for family income in the study makes allowances for spouse's income, number of children, taxes, and welfare benefits. It may therefore take some sources of bias in socioeconomic classification into account more effectively than other indicators. If a woman was employed, her social class was classified according to her own occupation. However, in some cases husbands' occupations may reflect the living conditions and social status of families more adequately. The value of education as a socioeconomic indicator is strongly dependent on age; in the older age groups there are very few women with higher education. ${ }^{23}$

In comparing our results regarding income and hysterectomy with those in previous studies, problems of incompatibility are met. Different definitions of income may be an explanation for differences in our results and those from other countries. Unlike our study, which used the quintiles of disposable family income, earlier studies often related hysterectomies to the absolute family income level (table 1).

Most earlier studies have been either ecological studies or population surveys. The ecological studies using geographical proxies for socioeconomic status are susceptible to the "ecological fallacy", and without a rather large sample size, population surveys based on the history of hysterectomies do not allow the assessment of present socioeconomic differences in surgery rates. Population surveys also have problems related to the time lag between hysterectomy and reported income, education, or occupational status. ${ }^{15}$ Education may be more stable, but occupational status and family income may change considerably over 10-20 years. Consequently, it is not, for instance, possible to compare in any useful way our results with those of the earlier Finnish population survey ${ }^{2}$ on the prevalence of hysterectomy.

The most conspicuous finding, which also explains the high hysterectomy rates in well off women in our study and may partly contribute to the high national hysterectomy rate in Finland compared with rates in similar countries ${ }^{6}$ is the high rate for myoma operations in women of high social status.

There are several potential explanations for this. Our results suggest that private medicine may create easier access to gynaecological procedures for the better off. In practice, Finland has a two tier health care system, in which the better off often consult gynaecologists privately, but those of low social status usually visit general practitioners in municipal health centres. Most private specialist services are provided by part time private practitioners who have full time jobs in hospitals. Private specialists can refer their patients to their own hospitals, either as pay bed (private) or regular patients. According to one survey, two thirds of pay bed patients were referred by the attending hospital doctors. ${ }^{24}$ This situation may create a financial incentive for gynaecologists who are simul- 
taneously practising privately and in public hospitals to recommend hysterectomy for women willing to be treated at a pay bed even if a more conservative treatment is an option. It has been suggested that private medicine may create socioeconomic disparities similar to those seen in hysterectomy for other procedures, such as cataract operations and prostatectomies, ${ }^{25}$ and this may also explain the high rates for surgical treatment of varicose veins in the well off and urban women in Finland. ${ }^{26}$ However, their better access does not necessarily explain the specific finding on high rates for myoma operations in women of high social status.

With regard to uterine diseases, we have morbidity data only for the incidence of and mortality from malignant conditions of the female genital tract. ${ }^{278}$ However, for myomas we have no data on morbidity in relation to socioeconomic group. Nor do we have data on patients' treatment preferences, which are, in addition to morbidity, important for operation decisions in discretionary surgery like myoma operations. Thus, the effect of these factors on socioeconomic differences cannot be evaluated.

One potential explanation for the high numbers of myoma operations in the better off women is that private gynaecologists may be more competent to diagnose uterine myomas than GPs in municipal health centres. Women of higher social status are also likely to receive gynaecological examinations more often and regularly than the worse off. Consequently, the probability of myomas being diagnosed could be higher among women of higher status.

On the other hand the worse off, who usually consult GPs, may be admitted to hospital with menstrual disorders, a frequent symptom of myomas. In many cases, this admission diagnosis is subsequently recorded as a treatment diagnosis in the discharge register. The combined analysis of hysterectomies due to myoma and menstrual disorder did reduce the socioecononomic rate differences across social classes and educational levels, but the clear gradient according to disposable income remained.

Finally, it is also possible that the high rates of myoma operations in the well off are related to their fewer pregnancies ${ }^{29}$ or the higher use of hormone replacement therapy for menopause symptoms ${ }^{30}$ in these groups in Finland. Low parity has been observed to be related to the probability of hysterectomy due to myoma ${ }^{13}$ and to the sizes of uterine myomas. ${ }^{31}$ The growth of myoma is considered to be dependent on oestrogen and probably on progestin as well, ${ }^{32}$ and in a recent study ${ }^{33}$ the number and size of myomas were observed to increase during hormone replacement therapy.

Even if there are clear socioeconomic differences in hysterectomy rates and they are obviously partly explained by better access to gynaecological services in the better off, it is difficult to judge whether our findings display socioeconomic inequities. The socioeconomic differences were systematic only for myoma operations, which do not have clear criteria for treatment. Treatment decisions on myoma, as well as on other benign uterine conditions, are often based on subjective symptoms and patient preferences, which are difficult to evaluate. Moreover, it is currently known that hysterectomies may have adverse outcomes, such as complications or long term cardiovascular disorders. ${ }^{34}$ Thus, in terms of health outcomes, it is difficult to say who are favoured - the better off with high rates or the worse off with low rates. More research is needed on decision making in hysterectomy and on the outcomes of all surgical as well as non-surgical treatments of gynaecological conditions.

1 Coulter A, McPherson K, Vessey M. Do British women undergo too many or too few hysterectomies. Soc Sci Med 1988;27:987-94.

2 Luoto R, Hemminki E, Topo P, Uutela A, Kangas I. Hysterectomy among Finnish women-prevalence and women's own opinions. Scand f Soc Med 1992;20:209-12.

3 Luoto R, Kaprio J, Keskimäki I, Pohjanlahti J-P, Rutanen E-M. Incidence, causes and surgical methods for hysterectomy in Finland, 1987-89. Int $\mathcal{F}$ Epidemiol 1994;23: 348-358.

4 McPherson K, Wennberg JE, Hovind OB, Clifford P. Smallarea variations in the use of common surgical procedures: area variations in the use of common surgical procedures: and Norway. $N$ Engl $\mathscr{F}$ Med 1982;307:1310-14.

5 Keskimäki I, Aro S, Teperi J. Regional variation in surgical procedure rates in Finland. Scand $\mathcal{F}$ Soc Med 1994;22: 132-38.

6 Madsen M, Andersen TF, Roepstorff C, et al. Rates of surgery in the Nordic countries. Variation between and within nations. Copenhagen: NOMESCO 1994:43.

7 Bunker J P, Brown B W. The physician-patient as an informed consumer of surgical services. $N$ Engl $₹$ Med 1974 290:1051-55.

8 Koepsell T D, Weiss N S, Thompson D J, Martin D P Prevalence of prior 34 hysterectomy in the Seattle-Tacoma area. Am $₹$ Public Health 1980;70:40-47.

9 Coulter A, McPherson K. Socioeconomic variations in the use of common surgical operations. BMF 1985;291:18387 .

10 Meilahn E N, Matthews K A, Egeland G, Kelsey S F Characteristics of women with hysterectomy. Maturita 1989;11:319-29.

11 Schofield MJ, Bennett A, Redman S, Walters WAW, SansonFisher R W. Self-reported long-term outcomes of hysterectomy. Br f Obstet Gynaecol 1991;98:1129-36.

12 Gittelsohn A M, Halpern J, Sanchez R L. Income, race, and surgery in Maryland. Am $\mathcal{F}$ Public Health 1991;81: 1435-41.

13 Vessey M P, Villard-Mackintosh L, McPherson K, Coulter A, Yeates D. The epidemiology of hysterectomy: findings in a large cohort study. $B r \mathcal{F}$ Obstet Gynaecol 1992;99: in a large 7 .

14 Santow G \& Bracher M. Correlates of hysterectomy in Australia. Soc Sci Med 1992;34:929-42.

15 Kjerulff K, Langenberg P, Guzinski G. The socioeconomic correlated of hysterectomies in the United States. $A m \mathcal{F}$ Publ Health 1993;83:106-8.

16 Kuh D, Stirling S. Socioeconomic variation in admission for diseases of female genital system and breast in a national cohort aged 15-43. BMF 1995;311:840-43.

17 Nikiforov O. General hospital care in Finland in the 1960s and 1970s. (In Finnish.) Helsinki: Health Services Research by the National Board of Health in Finland 32, 1984.

18 Keskimäki I, Aro S. Accuracy of data on diagnosis, procedures and accidents in the Finnish hospital discharge register. Int 7 Health Sciences 1991;2:15-21.

19 Central Statistical Office of Finland. Classification of socioeconomic groups. Tilastokeskus: Hand books 17, 1989.

20 Organisation for economic co-operation and development. The OECD list of social indicators. Paris: OECD, 1982.

21 Toimenpidenimikkeistö 1983. (Codes for surgical procedures) Helsinki: Finnish Hospital League, 1983.

22 Payne CD ed. The GLIM system, release 3.77, manual. Oxford: The Numerical Algorithms Group, Royal Statistical Society, 1985.

23 Rejneveld SA, Gunning-Schepers LJ. Age, health and the mever Eurf Public Health 1995;5:187-92.

24 Committee report on the development of ambulatory hospital care and freedom to choose the attending doctor (Hoitavan lääkärin valinnan ja poliklinikkatoiminnan kehittämistoimikunna mietintö, in Finnish). Helsinki: Komiteamietintö 1982: 19. Government Printing Centre, 1982.

25 Keskimäki I, Salinto M, Aro S. Private medicine and socioeconomic differences in the rates of common surgic procedures in Finland. Health Policy 1996;36:245-59.

26 Sisto T, Reunanen A, Laurikka J, Impivaara O, Heliövaara $\mathbf{M}$, Knekt $\mathbf{P}$ et al. Prevalence and risk factors of varicose veins in lower extremities: Mini-Finland Health Survey. Eur f Surg 1995;161:405-14.

27 Pukkala E. Cancer risk by social class and occupation. A 
survey of 109,000 cancer cases among Finns of working age. In: Wahrendorf J ed. Contributions to epidemiology and biostatistics. Vol 7. Basel: Karger, 1995 .

28 Valkonen T, Martelin T, Rimpelä A, Notkola V, Savela S. Socio-economic mortality differences in Finland 1981-90. Official Statistics of Finland, Population. Helsinki: Statistics Finland, 1993;1.

29 Nikander T. The women's life course and the family formation. Helsink: Statistics Finland, 1992; 1. Official Statistics of Finland, Population.

30 Topo P, Klaukka T, Hemminki E, Uutela A. Use of hormone replacement therapy in $1976-89$ by $45-64$ year old Finnish women. $\mathcal{F}$ Epidemiol Community Health 1991:45:277-80.
31 Shikora SA, Niloff JM Bistrian BR, Forse RA, Blackburn GL. Relationship between obesity and uterine leiomyomata. Nutrition 1991:7:251-55.

32 Rein MS, Barbieri RL, Friedman AJ. Progesterone: a critical role in the pathogenesis of uterine myomas. Am $\mathcal{F}$ Obstet Gynecol 1995:172:14-18.

33 Frigo P, Eppel W, Asseryanis E, et al. The effects of hormone substitution in depot form on the uterus in a group of 50 perimenopausal women - a vaginosonographic study. Maturitas 1995:21:221-25.

34 Luoto R, Kaprio J, Reunanen A, Rutanen E-M. Cardiovascular morbidity in relation to ovarian function after hysterectomy. Obstet Gynecol 1995;85:515-22. 